\title{
PERCEPÇÃO DE MORADORES DE CAHOEIRO DE ITAPEMIRIM QUANTO AS CARACTERÍSTICAS DA MATA ATLÂNTICA
}

\author{
Caroline Tavares Firmino ${ }^{1}$ \\ Gizely Azevedo Costa ${ }^{2}$ \\ Kamilla Matos Boldrini ${ }^{3}$ \\ Daiani Bernardo Pirovani ${ }^{4}$
}

Resumo: A Mata Atlântica representa um dos cinco principais Hotspots mundiais e, embora muito fragmentada, ainda é responsável pela oferta de inúmeros serviços ecossistêmicos. Objetivou-se, avaliar o conhecimento de moradores de um bairro de Cachoeiro de Itapemirim (ES) sobre características da Mata Atlântica. Foi aplicado um questionário composto por 20 questões divididas em 3 categorias, em que os respondentes deveriam julgar afirmativas referentes à Mata Atlântica como verdadeiras ou falsas. Foram entrevistadas 40 pessoas, sendo observado maior nível de conhecimento na categoria "Biodiversidade", e um conhecimento considerável em relação a "Geografia e clima" e "Conservação e serviços". Concluiu-se que a conservação deste bioma necessita da alteração da relação que a sociedade tem com o mesmo, o que é possível através da educação ambiental, mostrando aos cidadãos os bens e serviços prestados pelas florestas e sua importância para a humanidade.

Palavras-chave: Mata Atlântica; Educação ambiental; Questionário.

\footnotetext{
${ }^{1}$ Bacharelado em Ciências Biológicas/Instituto Federal do Espírito Santo - Campus de Alegre, Alegre, ES, Brasil. E-mail: tavares.carolini@gmail.com.

2 Bacharelado em Ciências Biológicas/Instituto Federal do Espírito Santo - Campus de Alegre, Alegre, ES, Brasil. E-mail: gizelyac.11@hotmail.com.

${ }^{3}$ Licenciatura em Ciências Biológicas/Instituto Federal do Espírito Santo - Campus de Alegre, Alegre, ES, Brasil. E-mail: kamillamb1994@gmail.com.

4 Professora Doutora/Instituto Federal do Espírito Santo - Campus de Ibatiba, Ibatiba, ES, Brasil. E-mail: daiani.pirovani@ifes.edu.br.
} 